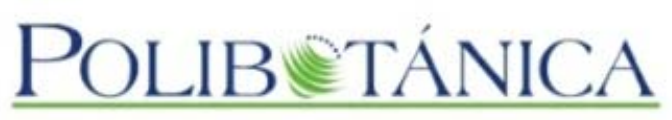

\title{
Polibotánica
}

ISSN electrónico: 2395-9525

polibotanica@gmail.com

Instituto Politécnico Nacional

México

http://www.polibotanica.mx

\section{CARACTERIZACIÓN SEMINAL Y DEL DESARROLLO DE Oenothera rosea L'Hér. ex Ait. EN INVERNADERO}

\section{CHARACTERIZATION OF SEEDS AND PLANT DEVELOPMENT OF Oenothera rosea L'Her. ex Ait IN GREENHOUSE}

\section{Romero-Sánchez, I.; C. B. Peña-Valdivia, A. García-Esteva y G. Aguilar-Benítez}

CARACTERIZACIÓN SEMINAL Y DEL DESARROLLO DE Oenothera rosea L'Hér. ex Ait. EN INVERNADERO

CHARACTERIZATION OF SEEDS AND PLANT DEVELOPMENT OF Oenothera rosea L'Her. ex Ait IN GREENHOUSE

\section{POLIBETÁNICA} Instituto Politécnico Nacional
Núm. 50: 47-66 México. Agosto 2020

DOI: $10.18387 /$ polibotanica.50.4

Este es un artículo de acceso abierto bajo la licencia Creative Commons 4.0 Atribución-No Comercial (CC BY-NC 4.0 Internacional). 


\title{
CARACTERIZACIÓN SEMINAL Y DEL DESARROLLO DE Oenothera rosea L'Hér. ex Ait. EN INVERNADERO
}

\section{CHARACTERIZATION OF SEEDS AND PLANT DEVELOPMENT OF Oenothera rosea L'Her. ex Ait IN GREENHOUSE}

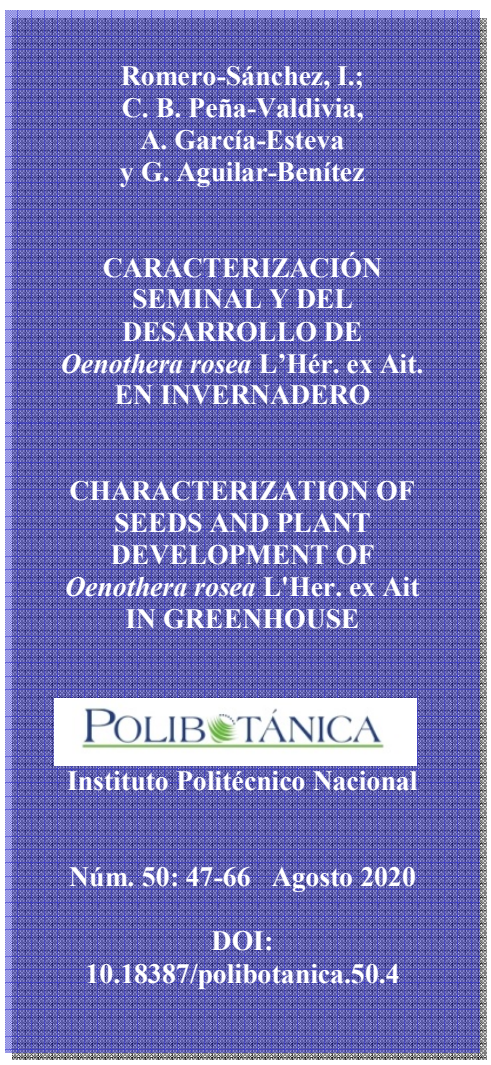

\author{
I. Romero-Sánchez \\ C. B. Peña-Valdivia / cecilia@colpos.mx \\ A. García-Esteva \\ Colegio de Postgraduados. Carretera México-Texcoco \\ km 36.5, Montecillo, Estado de México 56230. México. \\ G. Aguilar-Benítez \\ Instituto de Investigación de Zonas Desérticas, \\ Universidad Autónoma de San Luis Potosí \\ Altair 200, Colonia del Llano, 78377. San Luis Potosí, México.
}

RESUMEN: Oenothera rosea L'Hér. ex Ait. es una planta silvestre de la familia Onagraceae. Esta planta se reconoce por sus propiedades terapéuticas; por lo que, surge interés por cultivarla. El objetivo de este estudio fue caracterizar las semillas de $O$. rosea y el desarrollo de las plantas, en invernadero, hasta el final de la etapa reproductiva. La hipótesis fue que independientemente del sitio de recolecta y la variabilidad en tamaño de las semillas, las plantas de $O$. rosea responden al cultivo en condiciones protegidas. Las semillas se recolectaron en cuatro sitios del estado de Veracruz. El diseño experimental fue en bloques al azar generalizado, con 10 repeticiones ( 15 semillas por unidad experimental) para germinación y emergencia, y cuatro plantas por muestreo, cada 10 días, durante 110 días, para evaluar el crecimiento y la biomasa de las estructuras. Las plantas se cultivaron, en recipientes de $500 \mathrm{~mL}$ de capacidad, con turba vegetal, en un invernadero, de julio a septiembre de 2018 . La biomasa seminal promedio varió entre 0.0027 y $0.0091 \mathrm{~g}$. Entre 10 y $70 \%$ de semillas no germinaron en dependencia del tamaño de semilla y del sitio de recolecta. La proporción de semillas que no germinó varió entre 10 y $80 \%$ entre los sitios de recolecta. Ciento diez días después de la siembra, las plantas de semilla grande mostraron más altura del tallo (hasta $35 \%$ ), número de yemas florales $(60 \%)$, número de cápsulas maduras (el doble) y longitud de la raíz (27.2\%) respecto a las de semillas pequeñas. En contraste, el diámetro del tallo (a la altura del sustrato) y el número de hojas, su anchura y longitud fueron independientes del tamaño de la semilla. Las plantas de $O$. rosea crecen y se desarrollan vigorosas en invernadero; en poco más de 100 días de cultivo se asegura la disponibilidad de todos sus tejidos.

Palabras clave: crecimiento vegetativo; inflorescencias; semillas silvestres; yemas florales.

ABSTRACT: Oenothera rosea L'Hér. ex Ait. is a wild plant of the Onagraceae family. There is interest in its cultivation due its therapeutic properties. The objective in this study was to characterize $O$. rosea seeds and their plant development in a greenhouse environment, up to the end of their reproductive stage. The tested hypothesis was that regardless of the collection site and seed size variability, plants of $O$. rosea actively grow when developed under sheltered conditions. The assessed seeds were collected from four sites from the state of Veracruz. The experimental design consisted in generalized randomized blocks, with 10 repetitions ( 15 seeds per experimental unit) to 
assess germination and seedlings emergence, and four plants per sampling, every 10 days, for 110 days to evaluate growth and biomass of the plant structures. The plants were grown, in $500 \mathrm{~mL}$ containers, in peat moss, in a greenhouse, from July to September 2018. The mean seed biomass ranged between 0.0027 and $0.0091 \mathrm{~g}$. Between 10 and $70 \%$ of seeds did not germinate depending on the seed size and the collection site. After 110 days after sowing plants originated from large seeds were higher (up to $35 \%$ ), produced more flower buds $(60 \%)$, number of mature capsules (double) and longer roots $(27.2 \%)$ compared to plants from small seed plants. In contrast, stem diameter (at substrate height) and leave number, width and length were not related to the seed size. Oenothera rosea plants develop and grow vigorously in greenhouse conditions; all plant tissues are available 100 days after plant cultivation.

Key words: floral buds; inflorescences; vegetative growth; wild seeds.

\section{INTRODUCCIÓN}

La familia Onagraceae incluye a 22 géneros, organizados en 19 secciones; el género Oenothera destaca porque está representado por 192 especies de las 652 que integran a la familia; en la sección Hartmannia se ubica Oenothera rosea L'Hér. ex Ait. (Wagner, W. L., Hoch, P. C., y Raven, 2007). Con base en la distribución de sus parientes se concluyó que la especie es originaria de América y se ha calificado como especie cosmopolita por su distribución (Tanigushi, S, Imayoshi, Y, Hatana, T, Yazaki, K, e Yoshida, 2002). Oenothera rosea es abundante en el sur de Texas y en México, pues está presente en 25 de las 33 entidades federativas (Villaseñor-Ríos, J. L., y Espinosa-García, 1998). Esta especie es común en El Salvador, a lo largo de los Andes y hasta el centro de Chile, también está presente en Jamaica, Bermudas y esporádicamente en California, Arizona, Florida, Cuba, Venezuela, la costa de Brasil y Argentina, en India, Nepal y Sudáfrica; su presencia también se reconoce en el sur de Francia, las Azores, las Canarias, Rhodesia, Birmania y China (Calderón de Rzedowski, G., y Rzedowski, 2001; Deng, Y-C., Hua, H. M., Li, J., y Lapinskas, 2001; Wagner, W. L., Hoch, P. C., y Raven, 2007).

Las plantas de Oenothera son anuales, bianuales o perennes, con tallos erectos, simples o ramificados con alrededor de $50 \mathrm{~cm}$ de altura. Las hojas superiores son alternas, oblanceoladas o estrechamente ovadas, en contraste con las hojas inferiores, que son sinuado-dentadas a pinnatífidas. Las inflorescencias son actinomorfas y tetrámeras (Ormeño, 2006). El fruto es una cápsula con longitud de alrededor de $2.5 \mathrm{~cm}$, con varias semillas pequeñas y desnudas con embrión recto o casi recto (Ferreyra, 1986; Soria, 1984).

Las especies de este género que se han naturalizado en el resto de los continentes se cultivan para ornato, como plantas de jardín y en maceta (Clough, E. A., Cameron, A. C., Heins, R. D., y Carlson, 2001; Wiesner, 1991). Además, las plantas silvestres y las cultivadas de esas especies también son alimento para humanos y animales (Deng, Y-C., Hua, H. M., Li, J., y Lapinskas, 2001) y se han incorporado a la herbolaria, tradicional y actual, y como materia prima para productos farmacéuticos en México y el resto del mundo (Andrade-Cetto, 2009; Deng, Y-C., Hua, H. M., Li, J., y Lapinskas, 2001; Greiner, S., y Köhl, 2014; Meckes, M., David-Rivera, A.D., Nava-Aguilar, V., y Jimenez, 2004).

Oenothera rosea se reconoce principalmente por sus propiedades terapéuticas tradicionales y, varias de ellas, comprobadas experimentalmente (Andrade-Cetto, 2009; Díaz P., H. V., Fuertes R., C., Whu W., D., Jurado T., D., Roque A., M., y Arroyo A., 2011; Gómez-Flores, R., ReynaMartínez R., Tamez-Guerra, P., y Quintanilla-Licea, 2012; Kaur, R., Ali, M., Dahiya, S. S., Sharma, S. K., Sultana, S., y Mir, 2017; Márquez-Flores, Y. K., Montellano-Rosales, H., Campos A., M. E., y Meléndez-Camargo, 2009; Martínez, 2015; Meckes, M., David-Rivera, A.D., Nava-Aguilar, V., y Jimenez, 2004; Sihuay-Torres, K., Pérez-Jimenez, V., TurriateVivar, C., Portillo-Yancachajlla, E., y Castro-Rodríguez, 2016). La planta completa o sus estructuras separadas: flores, hojas, raíz, semillas o tallos, se usan tradicionalmente como 
analgésico, desinfectante, desinflamante, antihematómico y cicatrizante, para disminuir o eliminar los síntomas de infecciones de la piel, diarrea y trastornos digestivos, renales y hepáticos, dolor de cabeza o estómago y tos (Almora-Pinedo, Y., Arroyo-Acevedo, J., HerreraCalderon, O., Chumpitaz-Cerrate, V., Hañari-Quispe, R., Tinco-Jayo, A., ... Figueroa-Salvador, 2017; Andrade-Cetto, 2009; Calva-Candelaria, N., Meléndez-Camargo, M. E., MontellanoRosales, H., Estrada-Pérez, A. R., Rosales-Hernández, M. C., Fragoso-Vázquez, M. J., ... Márquez-Flores, 2018; Dahiya, S. S., Kaur, R., y Sharma, 2012; Deng, Y-C., Hua, H. M., Li, J., y Lapinskas, 2001; Gómez-Flores, R., Reyna-Martínez R., Tamez-Guerra, P., y QuintanillaLicea, 2012; Villena N., C. A., y Arroyo A., 2012).

La caracterización de la calidad física y fisiológica de las semillas y del crecimiento de las plantas de $O$. rosea es necesaria para conocer las condiciones de siembra que permitan su multiplicación, producción y rendimiento mayor de estructuras que podrían utilizarse en herbolaria, materia prima para extracción de metabolitos secundarios y multiplicación para ornato. In situ, la especie se distribuye en encinares, bosques de coníferas, pastizales y matorrales xerófilos; además, es común en los alrededores de campos de cultivo, es una planta facultativa de día largo sin respuesta a la vernalización (Chouard, 1960; Villaseñor-Ríos, J. L., y Espinosa-García, 1998). En la literatura especializada la información de las características físicas de las semillas de $O$. rosea es mínima y sobre su fisiología no se localizó alguna referencia. Tampoco se ha documentado el crecimiento y desarrollo de las plantas. En contraste, la fisiología de las semillas, el crecimiento y desarrollo de las plantas, la regulación de la floración y requisitos para la vernalización de especies como O. biennis, O. fruticosa, O. longiflora L., O. stricta Lebed. ex Link y O. suaveolens Pers. se han descrito, debido a que sus plantas en maceta ya se comercializan (Chouard, 1960; Clough, E. A., Cameron, A. C., Heins, R. D., y Carlson, 2001; Clough, E. A., Cameron, A.C., Heins, R. D., y Carlson, 1999; Ensminger, P. A., y Ikuma, 1987; Ensminger \& Ikuma, 1987; Giménez, R., Sorlino, D. M., Bertero, H. D., y Ploschuk, 2013; Picard, 1965).

El objetivo del presente estudio fue caracterizar las semillas de $O$. rosea, evaluar su germinación, la emergencia de las plántulas y el desarrollo de las plantas en condiciones protegidas. La hipótesis fue que independientemente del sitio de recolecta y de la variabilidad en tamaño, las semillas las plantas de $O$. rosea pueden cultivarse en condiciones de invernadero.

\section{MATERIAL Y MÉTODOS}

El estudio se realizó en el laboratorio de Biofísica Vegetal y Fisiología Ambiental del Posgrado en Botánica y en un invernadero del Colegio de Postgraduados, en Montecillo, Estado de México ( $19^{\circ} 27^{\prime} \mathrm{N}, 98^{\circ} 54^{\prime} \mathrm{O}$ y $2220 \mathrm{~m}$ de altitud).

Las cápsulas de $O$. rosea se recolectaron, durante marzo y abril de 2018, en los alrededores de Barrio San Pedro, Tepepa, Municipio de Tlaquilpa, Veracruz (18 36’ 29' N, 97 $07^{\prime}$ O y 2434 $\mathrm{m}$ de altitud y clima templado tipo $\mathrm{Cb}(\mathrm{fm})\left(\mathrm{i}^{\prime}\right) \mathrm{gw}$ " de acuerdo con el sistema de clasificación de Köppen modificado por García) (García, 1988).

Las semillas se obtuvieron de las cápsulas recolectadas de plantas individuales de cuatro sitios diferentes. Cada uno tenía un número variable de plantas, mayor a 50 en un área de alrededor de $100 \mathrm{~m}^{2}$. En cada sitio se identificaron las plantas representativas y de ellas se eligió una al azar. De cada una se cosecharon sus cápsulas totales. Aleatoriamente se asignó un número, del uno al cuatro, a cada sitio. Las semillas se extrajeron de las cápsulas y se mantuvieron separadas por sitio en bolsas de papel, a temperatura del laboratorio, durante su evaluación.

La longitud, anchura y forma de las semillas, esta última de acuerdo a la descripción de Calderón de Rzedowski, G. (2001), de una muestra de 200 se determinaron con un microscopio 
estereoscopio. El tamaño de la semilla se determinó con un grupo de cinco tamices con diámetro de poro de $0.250,0.297,0.354,0.420$ y $0.500 \mathrm{~mm}$. Además, en muestras de 250 semillas se determinó la biomasa en una balanza analítica (SCIENTECH SA 120), con precisión de $0.0001 \mathrm{~g}$.

La germinación de las semillas se determinó en cajas Petri, con algodón y papel filtro humedecidos con agua destilada, como soporte, con el método descrito por ISTA (ISTA, 2005). Cada caja Petri con 15 semillas representó una unidad experimental y se evaluaron 10 repeticiones de cada tamaño de semilla, por individuo. Las unidades se mantuvieron a $25^{\circ} \mathrm{C}$, en oscuridad, dentro de una germinadora. El recuento de las semillas germinadas se hizo cada $12 \mathrm{~h}$ durante $700 \mathrm{~h}$. En muestras de semillas en germinación se observaron, en microscopio estereoscopio, las estructuras de las plántulas. En este estudio, debido a las dimensiones de las semillas, la germinación se consideró exitosa cuando el hipocótilo y la raíz emergieron de entre los cotiledones y alcanzaron al menos $0.3 \mathrm{~mm}$ de longitud, equivalente al $50 \%$ de longitud de la semilla.

La emergencia de las plántulas, evidenciada por la exposición de las hojas cotiledonales con longitud entre 1 y $4 \mathrm{~mm}$, se determinó en el invernadero. En bandejas con 200 cavidades, con turba vegetal (Peat Moss; SUNSHINE® SS\#3) humedecida con agua, se colocaron dos semillas por cavidad, a $1 \mathrm{~mm}$ de profundidad, y se aplicó riego diario con un aspersor manual. Diariamente se cuantificaron las plántulas que emergieron durante 35 días. La unidad experimental la representó un bloque de 15 cavidades y se evaluaron 10 repeticiones de cada tamaño de semilla.

El desarrollo de las plantas se evaluó en vasos de unicel de $500 \mathrm{~mL}$ de capacidad con turba vegetal (Peat Moss; SUNSHINE® SS\#3), humedecida con agua, se sembraron, a $1 \mathrm{~mm}$ de profundidad, las semillas de cada tamaño seleccionado. La unidad experimental fue una planta por vaso. Las pantas se regaron diariamente con agua y cada tercer día se regaron con solución Steiner (Steiner, 1984). A partir de la emergencia de las plántulas se hicieron mediciones cada $10 \mathrm{~d}$, durante $110 \mathrm{~d}$. Las evaluaciones incluyeron anchura y longitud de la hoja y diámetro del tallo al nivel del sustrato, con un vernier digital (Mitutoyo ${ }^{\circledR}$ ), y altura de la planta, con una regla flexible, se cuantificó el número de ramas principales y secundarias, hojas, yemas florales, inflorescencias, cápsulas verdes y maduras (secas) y longitud de la raíz. Durante el desarrollo también se cuantificó la biomasa húmeda y seca de esas estructuras; esta última después de secar las estructuras, hasta peso constante, en estufa (BLUEM M®) con aire circulante a $70^{\circ} \mathrm{C}$. La biomasa se determinó en balanza analítica (SCIENTECH SA 120) con precisión de $0.0001 \mathrm{~g}$.

El diseño experimental fue de bloques al azar generalizado con dos tratamientos. Los bloques estuvieron representados por los cuatro sitios de recolecta y los tratamientos por los tamaños de semilla. Por definición del modelo de bloques al azar generalizado, en cada bloque se incluyó el número suficiente repeticiones para evaluar el desarrollo de las plantas durante más de 100 días. Así, en el estudio se incluyeron 10 repeticiones de cada tratamiento para las evaluaciones cada 10 días, durante 110 días. Por lo que, en el estudio se evaluaron en total cerca de 900 plantas.

Los resultados se analizaron con ANDEVA, comparación múltiple de medias con el método de Tukey $(\mathrm{p} \leq 0.05)$ con el paquete estadístico SAS. Para conocer las tendencias de crecimiento y desarrollo de las estructuras de las plantas, los datos se ajustaron a modelos matemáticos, con el software SigmaPlot 11.

\section{RESUltados}

Las semillas fueron amarillentas, oblongas u obovoides-elipsoides y con superficie punticulada; su anchura y longitud varió de 0.3 a $0.5 \mathrm{~mm}$ y de 0.6 a $0.8 \mathrm{~mm}$. Las dimensiones de las semillas 
permitieron su separación en dos grandes grupos mediante tamices, con poro entre $0.250 \mathrm{y}$ $0.500 \mathrm{~mm}$ de abertura; así, las semillas se clasificaron en pequeñas y grandes. En estos dos grupos la biomasa seminal promedio varió entre 0.0027 y $0.0091 \mathrm{~g}$. La proporción de semillas en los grupos difirió significativamente $(p \leq 0.5)$ dentro y entre los sitios, la excepción fue el sitio 2 sin diferencia entre las proporciones $(p>0.05)$. La diferencia en la biomasa media de las semillas grandes por sitio $(p>0.05)$ representó entre $23.6 \%$ respecto a las pequeñas, en el sitio 1 , y $68.6 \%$ en el sitio 4 (fig. 1 ).

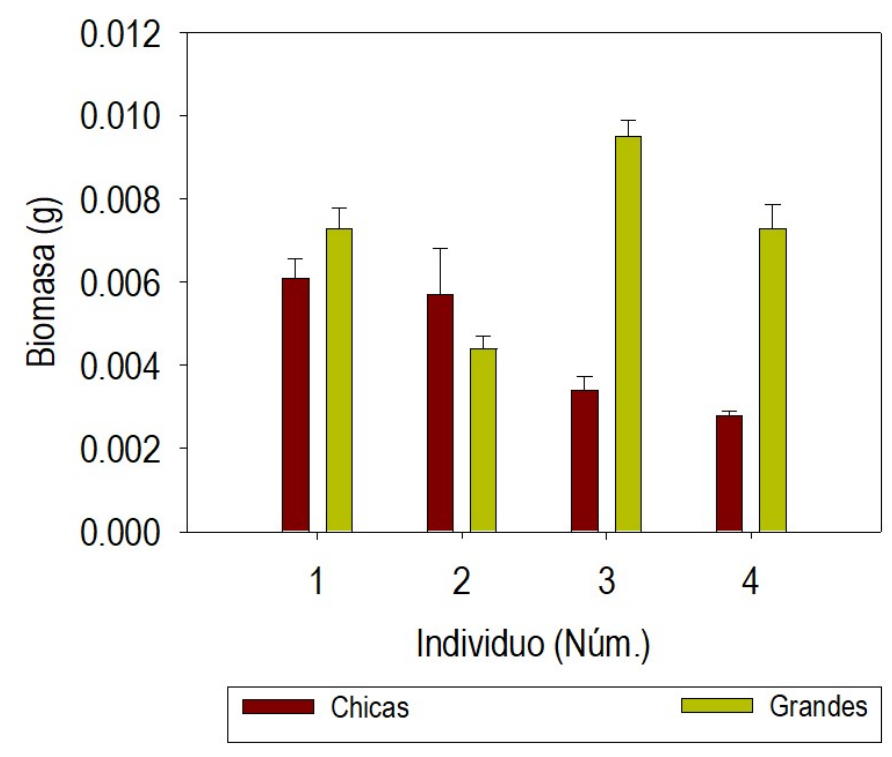

Fig. 1. Biomasa de semillas pequeñas y grandes, separadas a través de tamices con poro entre 0.50 y $0.25 \mathrm{~mm}$, de Oenothera rosea recolectadas en Tlaquilpa, Veracruz $n=250$.

Una prueba preliminar de germinación, en condiciones de laboratorio $\left(21 \pm 3{ }^{\circ} \mathrm{C}\right)$, mostró que gran proporción de las semillas de las cuatro recolectas eran viables y germinaron con relativa sincronía; además, en 4 o 5 días las plántulas expusieron sus hojas cotiledonales. Por lo que, el método estándar (ISTA, 2005) se aplicó para cuantificar los parámetros de la germinación. La germinación acumulada de las semillas generó curvas de tipo sigmoideo $\left(\mathrm{y}=\mathrm{a} / 1+\mathrm{e}^{-(\mathrm{x}-\mathrm{x}} 0^{/ b)}\right.$, con $\mathrm{r}^{2}$ entre 0.806 y 0.910 y $p \leq 0.0001$ ) (fig. 2). Las diferencias en el tiempo para iniciar la germinación, el porcentaje máximo acumulado y el tiempo para alcanzar este último fueron significativas $(p \leq 0.05)$ entre y dentro de los sitios muestreados. El tiempo para iniciar la germinación varió entre $72 \mathrm{~h}$, en las semillas del sitio 3, y $132 \mathrm{~h}$ en el sitio 4, en ambos tamaños de semillas (fig. 2 A-B).

La germinación seminal máxima entre las semillas pequeñas varió entre $21.33 \%$, en las del sitio 4, y $74.7 \%$, en el sitio 1 (fig. 2A). Entre las semillas grandes la fluctuación fue de 60 a $88.7 \%$, en las del sitio 4 y las de los sitios 1 y 3 (fig. 2B). Además, el tiempo para la germinación máxima acumulada difirió parcialmente entre tamaños de semilla y sitios de recolecta. Independientemente del porcentaje de germinación, las semillas pequeñas de los sitios 2,3 y 4 tardaron $360 \mathrm{~h}$ para obtener la germinación máxima y las del sitio 1 la alcanzaron $12 \mathrm{~h}$ después $(372 \mathrm{~h})$ (fig. 2A). En el caso de las semillas grandes el tiempo para obtener la germinación máxima difirió entre $324 \mathrm{~h}$ en el sitio $3,372 \mathrm{~h}$ en el 2 y 384 h en el 1 y 4 (fig. 2B). 


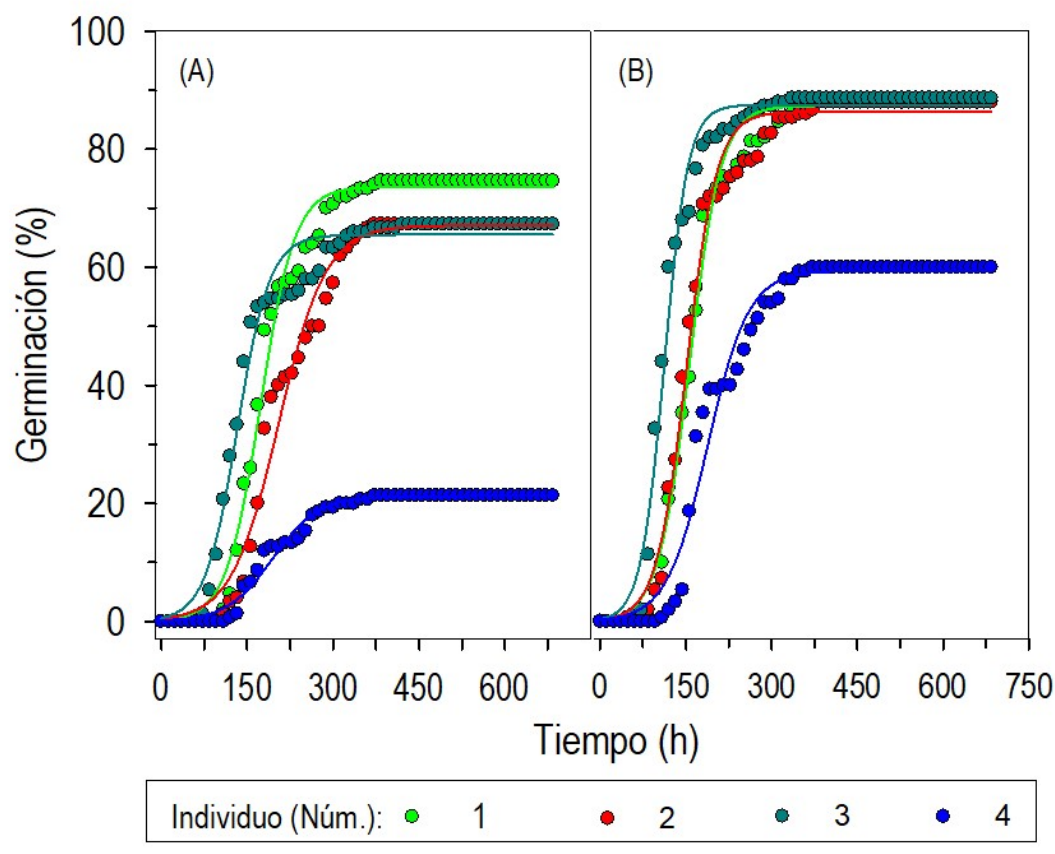

Fig. 2. Germinación acumulada a $21 \pm 3{ }^{\circ} \mathrm{C}$, en obscuridad, de semillas pequeñas (A) y grandes (B), separadas a través de tamices con poro entre 0.50 y $0.25 \mathrm{~mm}$, de Oenothera rosea recolectadas en Tlaquilpa, Veracruz; $n=10$.

La emergencia acumulada de las plántulas generó curvas de tipo sigmoideo $\left(\mathrm{y}=\mathrm{a} / 1+\mathrm{e}^{-(\mathrm{x}-\mathrm{x}} 0^{/ b}\right)$, con $\mathrm{r}^{2}$ entre 0.568 y 0.864 y $p \leq 0.0001$ ) (fig. 3). Esta variable mostró diferencias significativas $(p \leq 0.05)$ en el tiempo para su inicio, en el porcentaje máximo acumulado y en el tiempo para alcanzarlo entre y dentro de los sitios de recolecta. El inicio de la emergencia de las plántulas a partir de las semillas pequeñas varió entre 7 días, con las de los sitios 3 y 4, y 10 días, con las de los sitios 1 y 2 (fig. 3A). Esto contrastó parcialmente con las semillas grandes, las de los sitios 3 y 4 emergieron en promedio en 6 días y las de los sitios 1 y 2 en 9 y 11 días (fig. 3B). La emergencia máxima de las plántulas a partir de las semillas pequeñas varió entre $56.67 \%$, en las del sitio 2, y $82.67 \%$ en las del 3 (fig. 3A). En el caso de las semillas grandes la variación estuvo entre 66.67 y $90.37 \%$, a partir de las semillas del sitio 2 y el 4 (fig. 3B). Las plántulas de las semillas pequeñas de este último sitio alcanzaron el porcentaje máximo de emergencia desde los 32 días después de la siembra (DDS) y las de los otros sitios lo alcanzaron entre los 29 y 34 DDS (fig. 3).

Las plantas en cultivo mostraron heterogeneidad en la altura en la etapa vegetativa y en la floración. El cambio de la longitud del tallo o altura de la planta del inicio del crecimiento al momento de la cosecha describió curvas de tipo sigmoideo $\left(\mathrm{y}=\mathrm{a} / 1+\mathrm{e}^{-(\mathrm{x}-\mathrm{x}} \mathrm{o}_{0} \mathrm{~b}\right)$, con $\mathrm{r}^{2}$ entre 0.709 y 0.957 y $p \leq 0.0001$ ) en todos los casos. El crecimiento de las plantas de semilla pequeña mostró altura promedio máxima entre 29.08 y $36.7 \mathrm{~cm}$ (fig. 4A) y las de semilla grande alcanzaron entre 34.30 y $39.15 \mathrm{~cm}$ (fig. 4B). En ambos grupos el crecimiento longitudinal del tallo decayó significativamente a partir de los 80 DDS. 


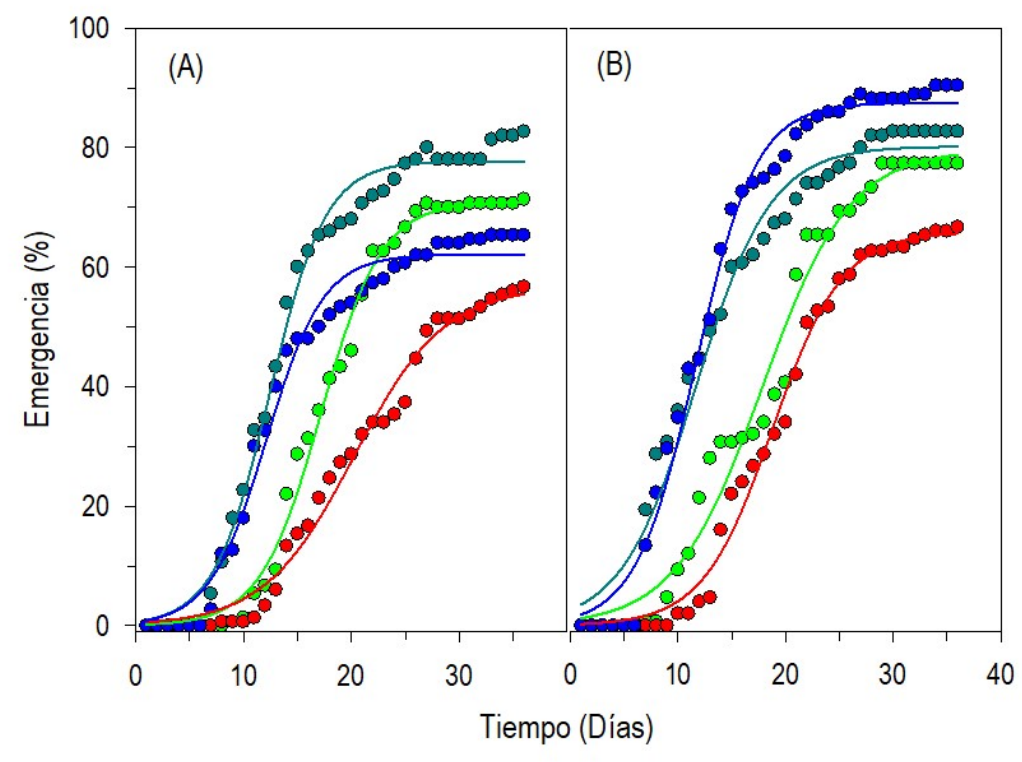

Individuo (Núm.): $\bullet \quad 1 \quad \bullet \quad 2 \quad \bullet \quad 3 \quad \bullet 4$

Fig. 3. Emergencia acumulada de plántulas Oenothera rosea en invernadero, a partir de semillas pequeñas (A) y grandes (B), separadas a través de tamices con poro entre 0.50 y $0.25 \mathrm{~mm}$, recolectadas en Tlaquilpa, Veracruz; $n=10$.

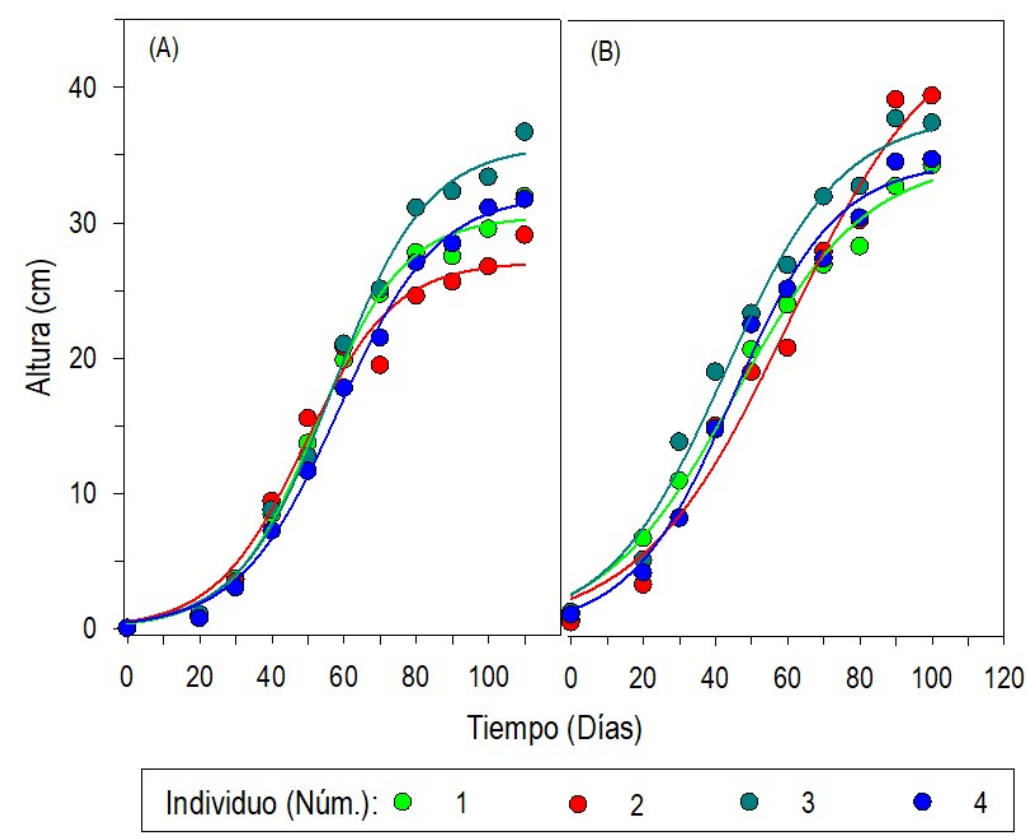

Fig. 4. Altura del tallo de plantas de Oenothera rosea en invernadero, a partir de semillas pequeñas (A) y grandes (B), separadas a través de tamices con poro entre 0.50 y $0.25 \mathrm{~mm}$, recolectadas en Tlaquilpa, Veracruz; $n=10$. 
El crecimiento transversal del tallo se ajustó al tipo polinomial de segundo orden $\left(\mathrm{y}=\mathrm{b}_{0}+\mathrm{xb}_{1}\right.$ $+\mathrm{x}^{2} \mathrm{~b}_{2} ; p \leq 0.05$ en todos los casos). Las plantas de las semillas pequeñas mostraron diámetro máximo entre 1.955 y $2.275 \mathrm{~cm}$ (fig. 5A) y las de las semillas grandes alcanzaron entre $1.798 \mathrm{y}$ $2.473 \mathrm{~cm}$ (fig. 5B). Con excepción de las plantas de la semilla grande del sitio 4, el crecimiento transversal del tallo continuaba aumentando a los 110 DDS.

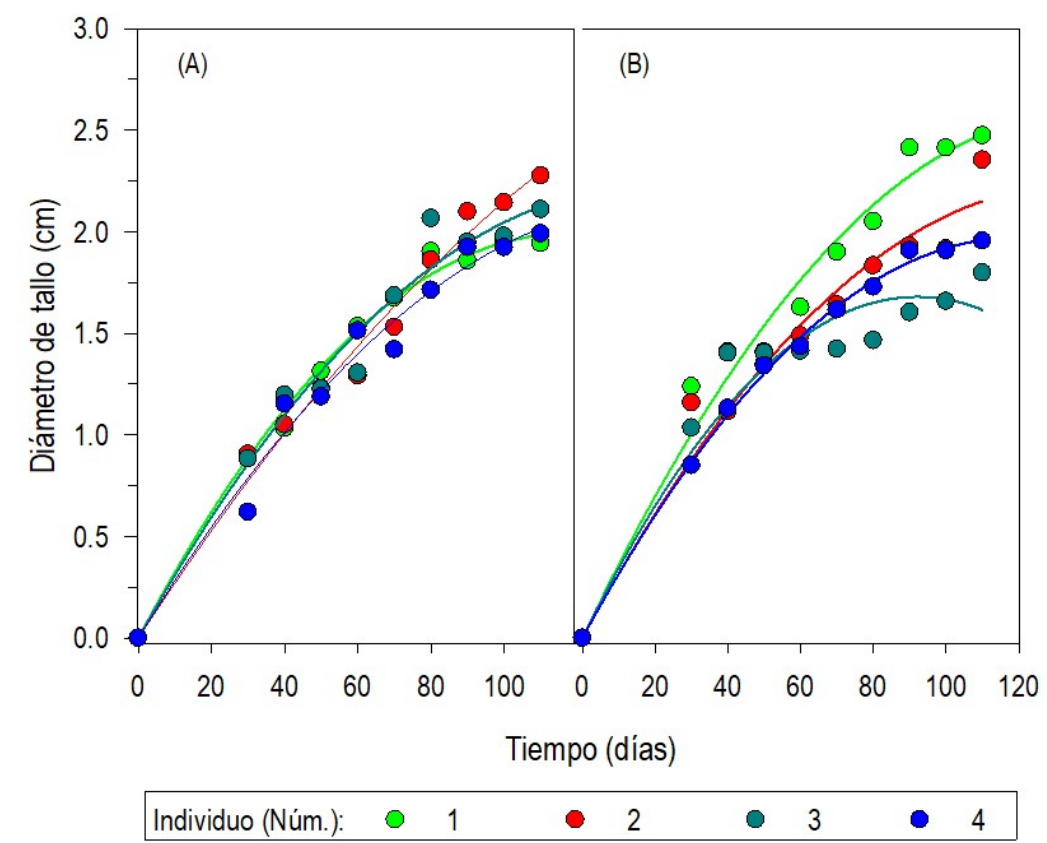

Fig. 5. Diámetro del tallo de plantas de Oenothera rosea en invernadero, a partir de semillas pequeñas (A) y grandes (B), separadas a través de tamices con poro entre 0.50 y $0.25 \mathrm{~mm}$, recolectadas en Tlaquilpa, Veracruz; $n=10$.

El crecimiento transversal promedio de la lámina foliar, durante el ciclo de crecimiento, mostró una tendencia Gaussiana $\left(\mathrm{y}=\mathrm{y}_{0}+\mathrm{a} e^{(-0.5(\mathrm{x}-\mathrm{x} 0 / \mathrm{b}) 2}\right)$; con $\mathrm{r}^{2}$ entre 0.832 y 0.999 en todos los casos. El follaje de las plantas de las semillas pequeñas mostró la anchura promedio mayor, alrededor de $12 \mathrm{~mm}, 60 \mathrm{DDS}$ (fig. $6 \mathrm{~A}$ ). La anchura foliar de las plantas de semilla pequeña incrementó del inicio hasta los 40 o 60 DDS y alcanzó valores máximos entre 10.86 y $12.48 \mathrm{~mm}$. Debido a la renovación continua del follaje, los siguientes 40 o 50 días la anchura foliar promedio disminuyó en las plantas de los ocho grupos (fig. 6 A-B). Es decir, el valor promedio disminuyó por la presencia de hojas en crecimiento. El crecimiento en anchura foliar de las plantas de semilla grande fue similar a la descrita por las plantas de semilla pequeña (fig. 6 B). 


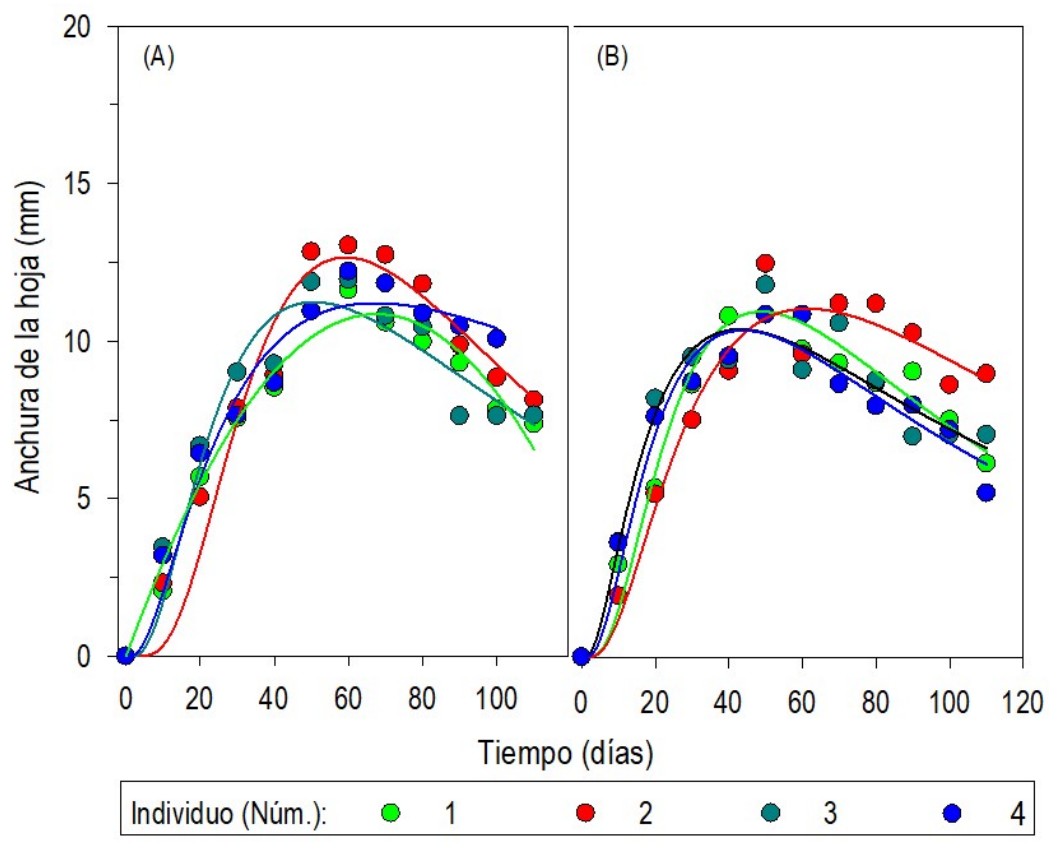

Fig. 6. Anchura de las hojas de plantas de Oenothera rosea en invernadero, a partir de semillas pequeñas (A) y grandes (B), separadas a través de tamices con poro entre 0.50 y $0.25 \mathrm{~mm}$, recolectadas en Tlaquilpa, Veracruz; $n=10$.

El crecimiento longitudinal promedio de la lámina foliar, durante el periodo de evaluación, mostró algunos patrones diferentes dependientes del tamaño de semilla que originó a las plantas (fig. 7A-B). En las plantas de semilla pequeña de los cuatro sitios y de semilla grande de los sitios 1 y 4 el crecimiento longitudinal foliar describió tendencia Gausiana $\left(\mathrm{y}=\mathrm{y}_{0}+\mathrm{a} e^{(-0.5(\mathrm{x}-\mathrm{t}}\right.$ $\mathrm{x} 0 / \mathrm{b}) 2$ ), con $\mathrm{r}^{2}$ entre 0.981 y 0.999 . Las hojas de esas plantas mostraron longitud promedio máxima $(28 \mathrm{~mm})$, alrededor de los 60 DDS. Como en el caso de la anchura foliar, la longitud también se modificó en las últimas etapas de desarrollo debido a la renovación del follaje. La diversidad de la respuesta al ambiente de cultivo entre los tamaños de semilla y sitios de muestreo se observó en la tendencia de crecimiento foliar longitudinal; ya que, en el caso de las plantas de semilla grande de los sitios 2 y 3 la longitud foliar se mantuvo relativamente constante en el periodo final, por crecimiento foliar mayor o renovación menor del follaje. Esto último se confirmó con la evaluación del número de hojas (fig. 8).

El incremento del número de hojas en el periodo de evaluación se ajustó al tipo polinomial de segundo orden $\left(\mathrm{y}=\mathrm{b}_{0}+\mathrm{xb}_{1}+\mathrm{x}^{2} \mathrm{~b}_{2} ; p \leq 0.05\right)$. Las plantas de ambos tamaños de semilla expusieron hojas en el periodo completo de 110 días de cultivo. Aunque, algunas plantas de semilla grande, como las del sitio 2, mostraron tendencia de incremento continuo hasta los 110 DDS. En promedio, las plantas de semilla pequeña acumularon máximos de 15 y 17.5 hojas por planta y las de semilla grande de 16.5 y 21.8 (fig. 8A-B). 


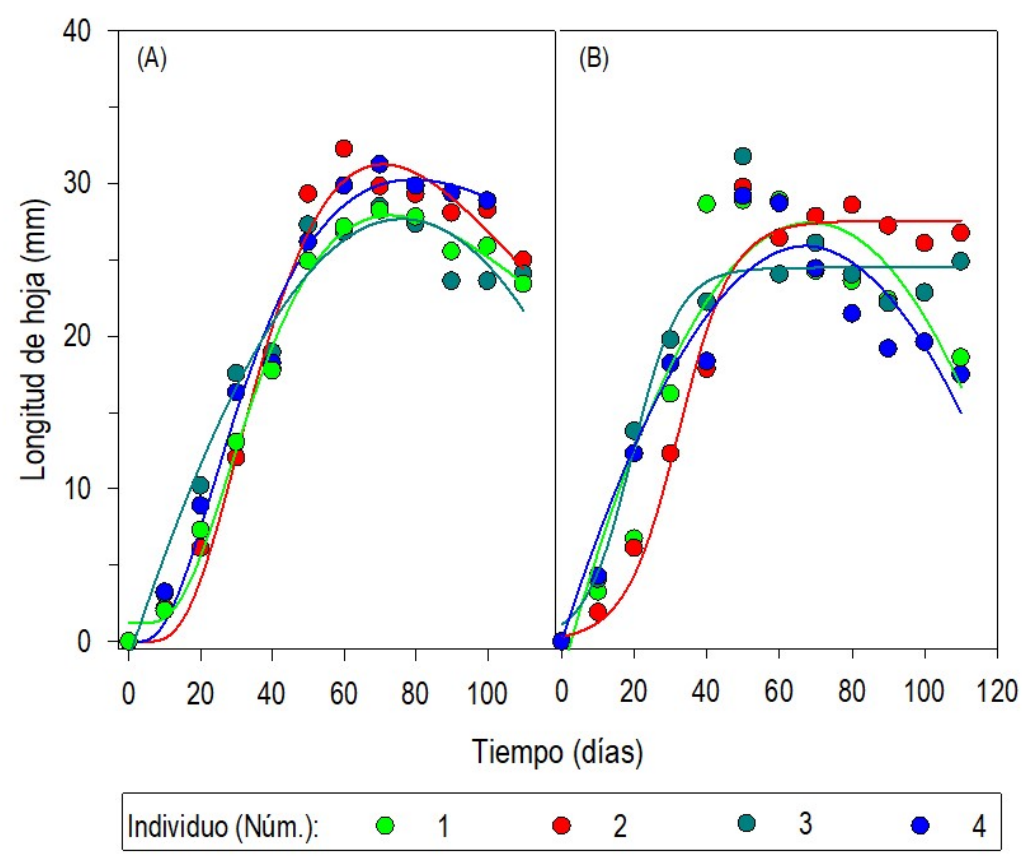

Fig. 7. Longitud de las hojas de plantas de Oenothera rosea en invernadero, a partir de semillas pequeñas (A) y grandes (B), separadas a través de tamices con poro entre 0.50 y $0.25 \mathrm{~mm}$, recolectadas en Tlaquilpa, Veracruz; $n=10$.

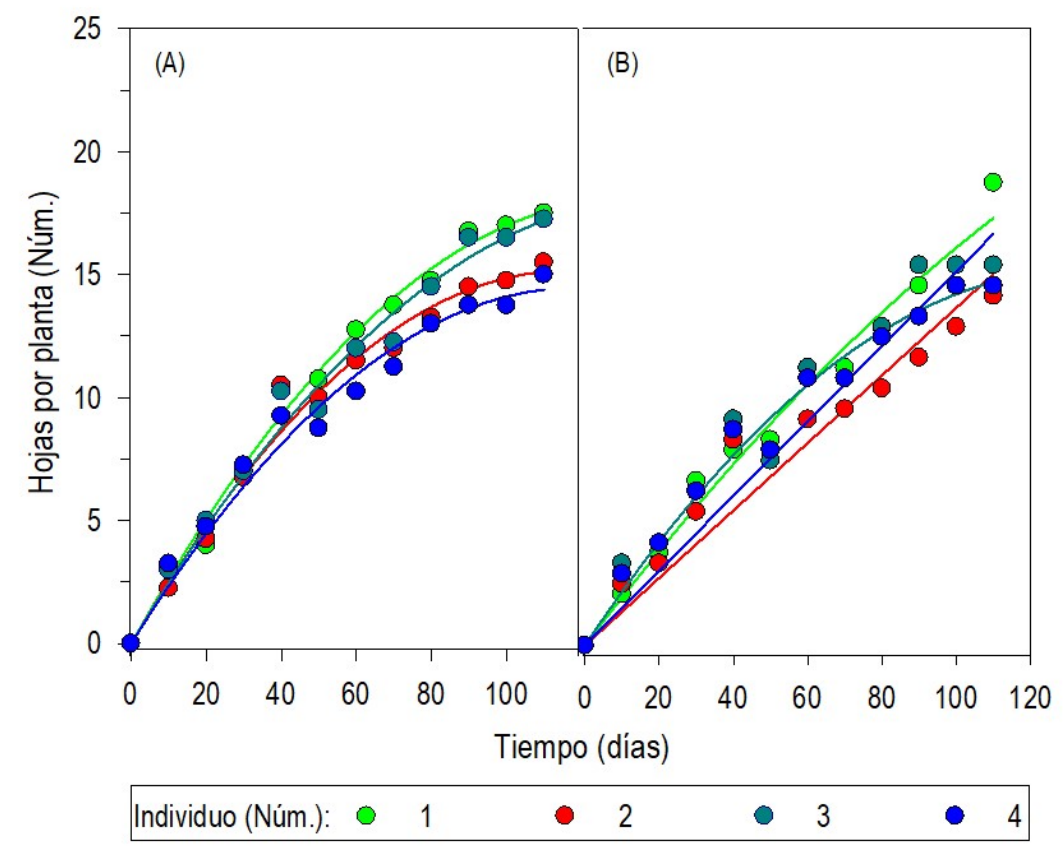

Fig. 8. Número de hojas por planta de Oenothera rosea en invernadero, a partir de semillas pequeñas (A) y grandes (B), separadas a través de tamices con poro entre 0.50 y $0.25 \mathrm{~mm}$, recolectadas en Tlaquilpa, Veracruz; $n=10$. 
Otras estructuras que se evaluaron, y son parte de los componentes del rendimiento, fueron ramas primarias, ramas secundarias, yemas florales, inflorescencias, cápsulas inmaduras y cápsulas maduras. Algunos de estos componentes del rendimiento, como el número de ramas secundarias y las estructuras reproductivas, excepto el de las inflorescencias, continuaba incrementando 110 DDS, independientemente del tamaño de la semilla que originó las plantas. Sin embargo, en general los valores máximos mayores los presentaron las plantas de semilla grande. Entre las cantidades de las estructuras destacaron las yemas florales y las cápsulas maduras, que a los 110 DDS eran $60 \%$ y el doble más $(p \leq 0.05)$ en estas plantas, respecto a las obtenidas de semillas pequeñas (fig. 9).

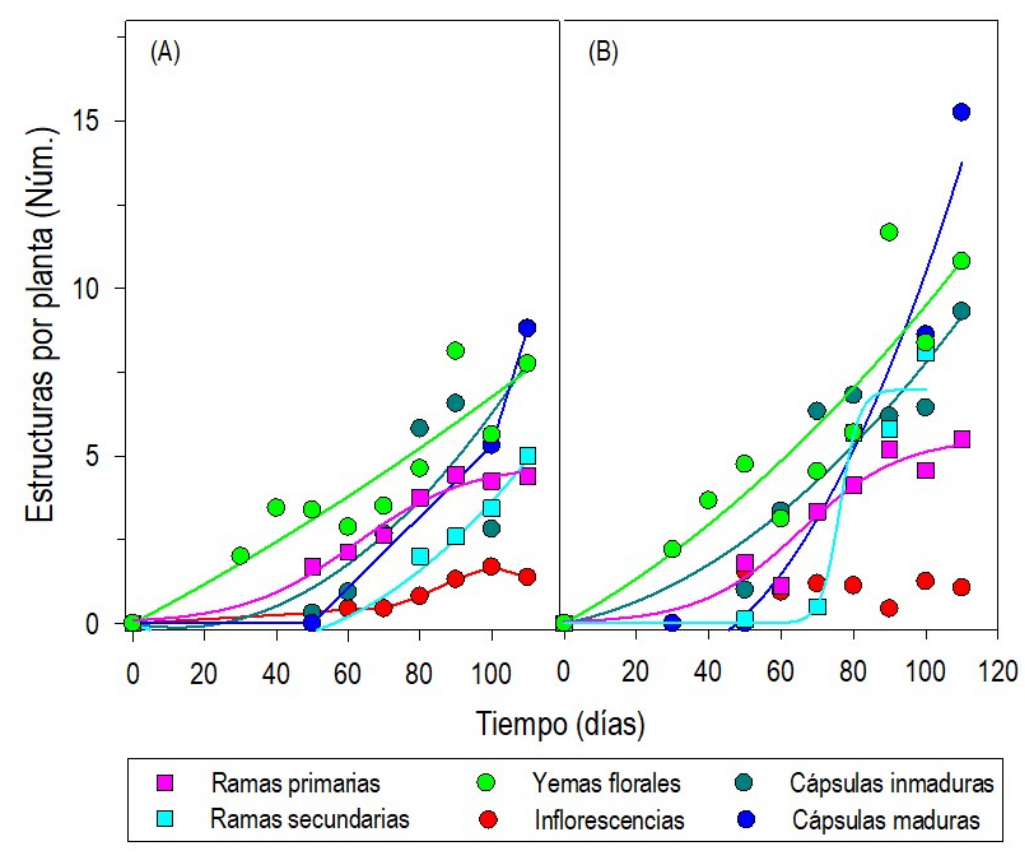

Fig. 9. Número de estructuras vegetativas y reproductivas por plantas de Oenothera rosea en invernadero, a partir de semillas pequeñas (A) y grandes (B), separadas a través de tamices con poro entre 0.50 y $0.25 \mathrm{~mm}$, recolectadas en Tlaquilpa, Veracruz; $n=10$.

La biomasa se registró en hojas, tallos más ramas, raíz, yemas florales, inflorescencias y cápsulas. Las inflorescencias mantuvieron la biomasa sin cambios significativos entre los $50 \mathrm{y}$ 110 DDS. En contraste, en las yemas florales incrementó significativamente $(p \leq 0.05)$ a partir de los 80 DDS. El incremento promedio mayor de estas estructuras reproductivas se observó $(0.113 \mathrm{~g})$ a los 100 DDS en las plantas derivadas de semillas pequeñas. En las plantas obtenidas de semillas grandes el incremento se mantuvo hasta los 110 DDS, pero en promedio representó $(0.035 \mathrm{~g})$ cerca de la cuarta parte que en las plantas derivadas de semilla pequeña (fig. $10 \mathrm{~A}-\mathrm{B})$.

El incremento significativo mayor $(p \leq 0.05)$ de biomasa seca se observó, a los 110 DDS, en conjunto en el tallo y las ramas, en las hojas y en las cápsulas de ambos grupos de plantas. Sin embargo, en tres casos las plantas de semilla grande presentaron hasta $40 \%$ más que en las plantas de semilla pequeña (fig. 10A-B). 


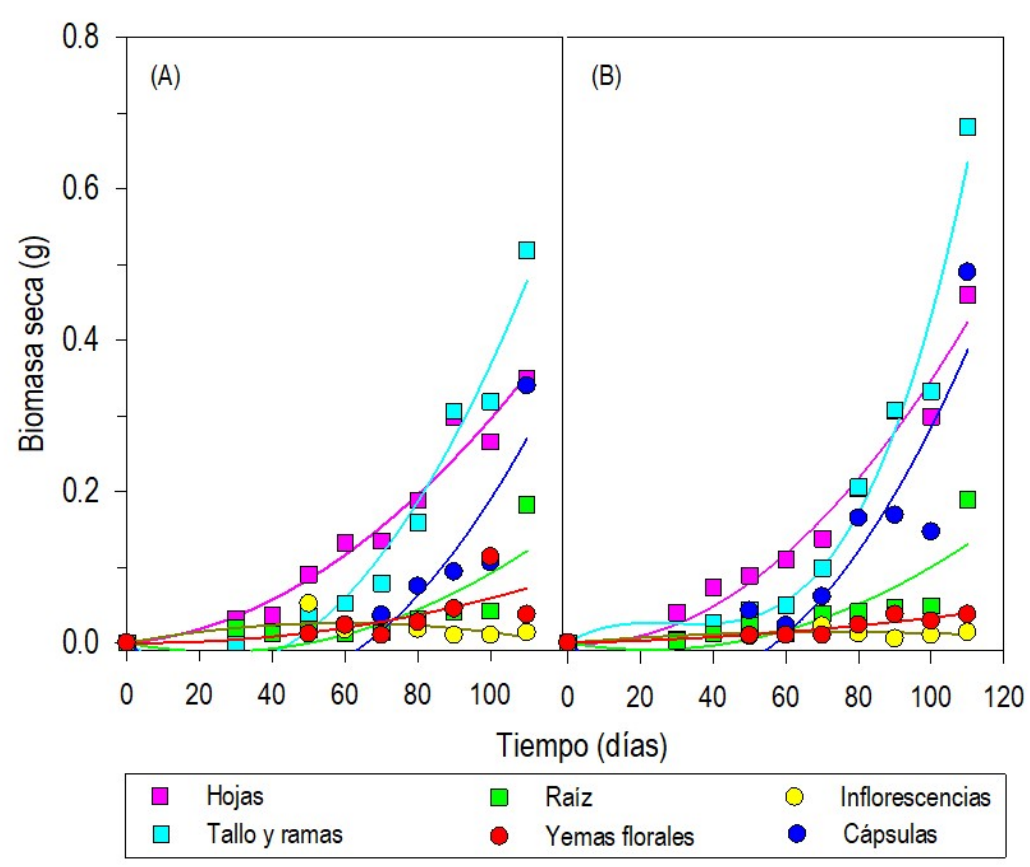

Fig. 10. Biomasa seca acumulada en las estructuras vegetativas y reproductivas y raíz de plantas de Oenothera rosea en invernadero, a partir de semillas pequeñas (A) y grandes (B), separadas a través de tamices con poro entre 0.50 y $0.25 \mathrm{~mm}$, recolectadas en Tlaquilpa, Veracruz; $n=10$.

La raíz tendió a incrementar su biomasa seca en los primeros 100 DDS, pero el incremento significativo se observó 10 días después; además, la biomasa máxima acumulada fue similar ( $p$ $>0.05$ ) entre los grupos (fig. 10). En contraste con la estabilidad relativa de la biomasa en la raíz de ambos grupos, la longitud de esta estructura incrementó continuamente durante los 110 días. Esta característica fue significativamente diferente $(p \leq 0.05)$ entre los dos grupos de plantas a los 100 y 110 DDS. Las plantas de semillas grande desarrollaron raíces hasta $27.2 \%$ más largas respecto a las obtenidas de semillas pequeñas (fig. 11).

\section{DISCUSIÓN}

El tamaño de la semilla es parte de la aptitud evolutiva en las plantas y un rasgo agronómico en la domesticación. Las semillas grandes acumulan más reservas nutritivas para la germinación y la emergencia de las plántulas que las semillas pequeñas y estas últimas son eficientes en la dispersión y la colonización (Moles, A. T., Ackerly, D. D., Webb, C. O., Tweddle, J. C., Dickie, J. B., y Westoby, 2005). En el presente estudio la variación del tamaño de semilla permitió separar sólo dos grupos de semillas, independientemente del sitio de recolecta. La variabilidad entre tamaños de semilla de los cuatro sitios muestreados mostró cierta amplitud, pero sobresalió que en dos de ellos la proporción de semillas pequeñas y grandes fuera significativamente similar y su diferencia con las otras dos, en las que la abundancia de semillas grandes fue más del doble que las pequeñas. Además, la variabilidad dentro y entre sitios se confirmó con el coeficiente de variación (C.V.) que representó entre $8.14 \%$, en las semillas pequeñas del sitio 4 , y $46.81 \%$, en el mismo tamaño del sitio 2 . Desde el inicio de la agricultura, el tamaño mayor de semilla se ha seleccionado durante la domesticación de las plantas para cultivo (Fan, C., Yu, S., Wang, C., y Xing, 2009). En especies como Arabidopsis thaliana, Brassica napus y Glycine max la variación del tamaño puede ser de varias decenas de 
veces. Sin embargo, la cuestión de cómo define la planta el tamaño de sus semillas es poco conocido (Li N., y Li, 2015).

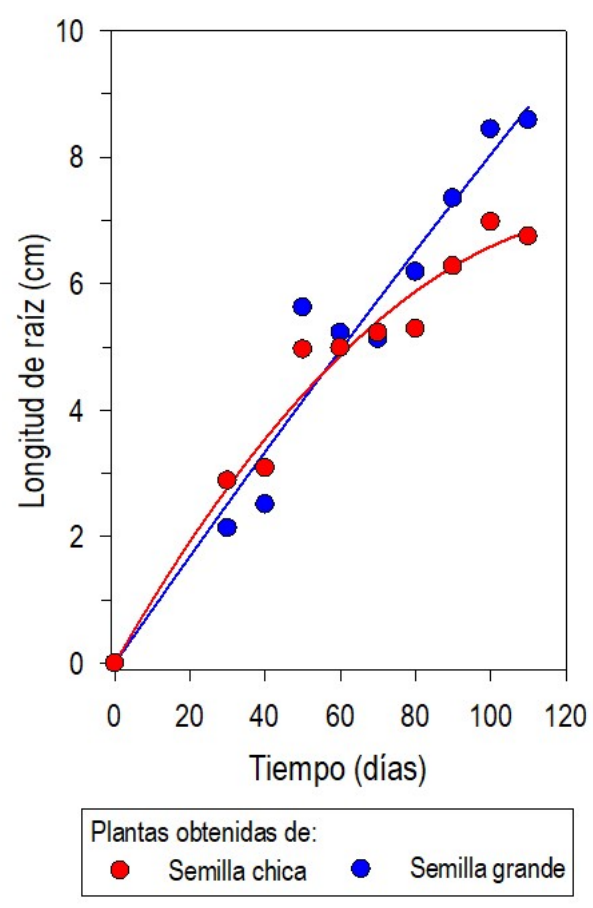

Fig. 11. Longitud de la raíz de plantas de Oenothera rosea en invernadero, a partir de semillas pequeñas (A) y grandes (B), separadas a través de tamices con poro entre 0.50 y $0.25 \mathrm{~mm}$, recolectadas en Tlaquilpa, Veracruz; $n=10$.

En este estudio, para caracterizar las semillas evaluamos la variación del crecimiento y desarrollo de las plantas en relación con el tamaño seminal original hasta la etapa reproductiva, incluyendo la germinación de las semillas y emergencia de las plántulas en condiciones protegidas. Los hallazgos indicaron que el tamaño de semilla mayor proporciona ventajas para la germinación y el establecimiento de las plántulas; ya que sus porcentajes de germinación acumulada fueron los mayores y algunas de las variables que definen este proceso fisiológico fueron las más aceleradas. No obstante, la variabilidad general en la germinación y la emergencia máxima acumulada dentro y entre sitios, a partir de las semillas pequeñas fueron notablemente más heterogéneas, ya que el C.V. de la germinación varió entre 22.19 y $74.83 \%$ (en las semillas de los sitios 1 y 4 ) y el de la emergencia entre 18.31 y $40.47 \%$ (en las de los sitios 3 y 4). En contraste, en estos procesos el C.V. en las semillas grandes fue menor a $22.22 \%$.

Los resultados de este estudio pueden explicarse mediante el análisis de otras características fisiológicas de las semillas dependientes del tamaño. Las semillas grandes pueden carecer de la latencia, con lo que evitan condiciones desfavorables al beneficiarse de la germinación temprana después de la madurez y, así, maximizan su crecimiento antes del inicio de condiciones desfavorables (Brunner, I., Herzog, C., Dawes, M. A., Arend, M., y Sperisen, 2015). Por lo que, la latencia y el tamaño de las semillas son adaptaciones alternativas (Rees, M., y Venable, 2007). Sin embargo, el tamaño de las semillas está limitado por factores como el tamaño máximo de la planta adulta (Venable D. L., y Rees, 2009) y las semillas más grandes requieren asignación de más recursos, lo que se asocia con número menor de semillas 
producidas por planta, y el riesgo de depredación puede aumentar (Gómez J. M., y Husband, 2004).

La latencia de la semilla se ha interpretado como el carácter que proporciona ventajas ecológicas, ya que ajusta la germinación al período de crecimiento favorable. Sin embargo, muchas especies producen semillas no latentes, particularmente en bosques tropicales húmedos (Rubio de Casas, R., Willis, C. G., Pearse, W. D., Baskin, C. C., Baskin, J. M., y CavenderBares, 2017). En O. rosea las semillas que no germinaron, de las que una parte o todas podrían ser latentes, contrastó significativamente entre los tamaños de semilla dentro y entre los sitios de recolecta. La abundancia máxima de semillas no germinadas, dependiente del tamaño dentro de un mismo sitio, alcanzó $80 \%$ en las semillas pequeñas y $40 \%$ en las grandes. En contraste, las semillas pequeñas y grandes de los otros sitios mostraron 23 y $10 \%$ de semillas que no germinaron. Sin embargo, esas diferencias y los porcentajes parecen poco relevantes ante la respuesta de las semillas para generar plántulas cuando las semillas se sembraron en turba vegetal y condiciones de invernadero. Aunque, el inicio de la germinación tomó entre 2 y 7 días y la emergencia de plántulas entre 7 y 10 días, el incremento continuo, con tendencia sigmoidea, mostró que las semillas del sitio 4 (con porcentaje mayor de semillas no germinadas) alcanzaron $65 \%$ (semillas pequeñas) y $92 \%$ (semillas grandes) de plántulas emergidas en 32 días.

Los resultados de este estudio coincidieron parcialmente con los de Metz et al. (Metz, J., Liancourt, P., Kigel, J., Harel, D., Sternberg, M., y Tielbo, 2010) en 49 especies anuales. Ellos mostraron que en las especies anuales el tamaño mayor de semilla es ventajoso para la supervivencia desde el establecimiento de las plántulas hasta la reproducción. El tamaño mayor de semilla también mostró ventaja en entornos temporalmente impredecibles. Los mismos autores observaron resultados contrastantes entre leguminosas y gramíneas y sugirieron que pueden deberse en parte a la disparidad en la latencia seminal. El efecto positivo de las semillas grandes sobre la germinación y el crecimiento temprano de las plantas se ha observado en otras especies, como trigo (Triticum aestivum) (Gan, Y., y Stobbe, 1995) y lenteja (Lens culinaris) (Erskine, 1996); en contraste, el tamaño de las semillas no mostró efecto sobre su germinación en lenteja y trigo de invierno (Al-Karaki, 1998; Mian, M. A. R., y Nafziger, 1994). White et al. (White, I. W., Singh, S. P., Pino, C., Rios, M. J., y Buddenhagen, 1992) indicaron que el tamaño de la semilla estuvo asociado negativamente con el rendimiento de cultivares de frijol (Phaseolus vulgaris L.). En este caso, la variabilidad en las condiciones ambientales, como la humedad del suelo, se ha señalado que podría explicar algunas de las discrepancias (Jha, B. B., Sinha, S. K., y Singh, 1985).

La relación positiva entre el tamaño de la semilla y la subsiguiente supervivencia de la descendencia es un supuesto clave en la teoría ecológica sobre las estrategias de la historia de vida. Sin embargo, esta relación es incierta respecto de la supervivencia en el ciclo completo porque la evidencia sólida solo existe para las etapas iniciales de las plántulas (Metz, J., Liancourt, P., Kigel, J., Harel, D., Sternberg, M., y Tielbo, 2010); por lo que estudios que incluyan el ciclo de crecimiento y desarrollo, como el presente, son necesarios para completar la información. Turnbull et al. (Turnbull, L. A., Philipson, C. D., Purves, D. W., Atkinson, R. L., Cunniff, J., Goodenough, A., ... Rees, 2012) aseguraron que las especies de semillas pequeñas algunas veces poseen adaptaciones adicionales, respecto a las de tamaño mayor, para el crecimiento acelerado. Esto conduce a que las especies de semilla pequeña muestren tasas de crecimiento mayores en las poblaciones en ambientes en los que la competencia es mínima.

En el presente estudio el tamaño de la semilla se asoció con ciertas variables del crecimiento de las plantas. Un caso fue la altura del tallo, que en promedio fue $12 \%$ mayor en las plantas de semilla grande; pero, específicamente en las que provenían de las semillas grandes del sitio 2 la diferencia alcanzó 35\%. El valor máximo de esta variable también fue heterogéneo entre y dentro de los sitios, independientemente del tamaño de semilla; pues el $C$. $V$. varió entre 9.79 y $33.57 \%$ en las plantas de semilla pequeña y entre 8.93 y $34.22 \%$ en las de semilla grande. En 
contraste, salvo alguna excepción, el tamaño de la semilla del que provenían las plantas no favoreció el diámetro del tallo o la anchura, la longitud o el número promedio de las hojas durante el crecimiento y 110 DDS.

La relación entre la masa de la semilla y el crecimiento de la planta se ha documentado en varios grupos vegetales (Poorter, L., Wright, S. J., Paz, H., Ackerly, D. D., Condit, R., IbarraManríquez, G., 2008) y mostró un gradiente que en un extremo presenta especies colonizadoras, que usan los eventos de perturbación o brechas, y en el otro extremo muestra especies lentas para colonizar o crecer, pero que pueden sobresalir en la competencia a largo plazo (Kitajima, K., y Myers, 2008). Pero las especies pioneras tendrán semillas pequeñas con tasas altas de crecimiento de la descendencia y la relación entre el tamaño de semilla y la tasa de crecimiento puede diferir entre hábitats y naturaleza de la competencia (Turnbull, L. A., Philipson, C. D., Purves, D. W., Atkinson, R. L., Cunniff, J., Goodenough, A., ... Rees, 2012). Por lo que, las respuestas del crecimiento en relación con el tamaño de semilla pueden diferir entre el hábitat propio y las condiciones de cultivo. En el caso de $O$. rosea, en la literatura no se ha documentado la caracterización física y fisiológica de sus semillas ni el crecimiento de sus plantas.

Entre las variables evaluadas, las dimensiones de las hojas sobresalieron por su variabilidad, independientemente del tamaño de la semilla originaria. El C.V. de la anchura foliar, representó 55.55 a $78.38 \%$ en las plantas de semilla pequeña y en las plantas de semilla grande representó porcentajes de 66.62 a 95.52 . Además, el $C . V$. de la longitud foliar representó entre 56 y $79 \%$ en las plantas de ambos tamaños de semilla. La heterogeneidad de ambas dimensiones foliares se debió a la exposición continua y asincrónica del follaje durante los 110 días de evaluación. En promedio durante los primeros 60 DDS las plantas de semilla pequeña incrementaron la anchura y la longitud de sus hojas; cada una de estas variables incrementó casi linealmente, en función del tiempo, en ese periodo inicial del crecimiento. Pero, en los siguientes 50 días ambas variables decayeron. Esta caída de la anchura y longitud promedio de las hojas se explica por la citada exposición de follaje nuevo, que, en este tiempo no había completado su expansión. A lo anterior se sumaría el efecto de la defoliación natural en las plantas que tiende a ser mayor en la etapa de maduración de las cápsulas. La renovación del follaje se comprobó parcialmente con el incremento cercanamente lineal y lineal del número de hojas por planta de semilla pequeña y grande, respectivamente, del inicio hasta los 110 DDS. Las plantas de semilla grande de los sitios 2 y 3 mostraron contraste en el cambio de la longitud promedio de la hoja durante el crecimiento de las plantas. Esta variable tendió a mantenerse sin cambio a partir de los 40 o 60 DDS. En contraste con la caída de la longitud foliar de las plantas de semilla pequeña y dos de semilla grande, estas plantas podrían haber mostrado menos defoliación, mayor crecimiento longitudinal, o ambos, de las hojas expuestas en la última etapa del desarrollo. Lo anterior permitió corroborar que el desarrollo de la planta de $O$. rosea en condiciones protegidas fue dependiente del tamaño de semilla y del sitio de recolecta. A la vez, indirectamente se confirmó que las condiciones edafoclimáticas particulares lo afectan y su dependencia de la interacción genotipo x ambiente. Al respecto, Elizalde et al. (Elizalde, V., García, J. R., Peña-Valdivia, C. B., Ybarra, M. C., Leyva, O. R., y Trejo, 2017) observaron que los patrones de precipitación, temperatura ambiente e irradiancia máxima, mínima y promedio diarios durante 12 meses previos a la recolecta de semillas de Hechtia perotensis, recolectad en Veracruz en dos años diferentes, mostraron relación con el porcentaje de semillas viables, su germinación y proporción de semillas sin embrión.

Las etapas fenológicas de $O$. rosea mostraron traslapo independientemente del tamaño de semilla. El traslapo de las etapas fenológicas se ha documentado en tipos silvestres de $P$. vulgaris, responsable de la asincronía del desarrollo de las plantas de esos tipos (Peña-Valdivia, C. B., Aguirre-Rivera, J. R., y Arroyo-Peña, 2012). El crecimiento longitudinal del tallo, la exposición de follaje y ramas primarias y secundarias y el incremento de la biomasa de estas estructuras definen la etapa vegetativa en herbáceas domesticadas, como frijol, maíz, chícharo, trigo, avena y otras especies (Peña-Valdivia, C. B., Aguirre-Rivera, J. R., y Arroyo-Peña, 
2012). En las plantas del presente estudio estas estructuras continuaron creciendo, en longitud, número o biomasa, desde el inicio de la etapa reproductiva y hasta los 110 DDS. Esta etapa inicia con la antesis, y continúa con exposición de yemas florales y exposición de inflorescencias y frutos, generalmente consume las reservas y fotoasimilados de órganos vegetativos (Aguirre R., J. R., Peña-Valdivia, C. B., y Bayuelo-Jiménez, 2003; Berrocal I., S., Ortíz C., J., y Peña-Valdivia, 2002). Por lo que, estos últimos disminuyen o detiene su crecimiento. En las plantas de $O$. rosea además del crecimiento de estructuras vegetativas durante los 110 DDS, la exposición continua de yemas florales desde los 30 DDS se traslapó con la formación de cápsulas y su maduración. Además, las plantas de semilla grande presentaron significativamente más número y biomasa de yemas florales y cápsulas maduras 110 DDS. El crecimiento en algunas estructuras vegetativas y reproductivas fue mayor en las plantas de semilla grande y coincidió con el crecimiento mayor de la raíz. Pérez et al. (Pérez, M. C., Hernández, L. A., González, C. F. V., García de los Santos, G., Carballo, C. A., Vásquez, R. T. R., y Tovar, 2006) observaron efecto del tamaño de semilla en la longitud y biomasa seca acumulada en la raíz de plantas de maíz para forraje. Los autores señalaron que el crecimiento mayor de este órgano se asocia con el tamaño mayor del embrión en las semillas, ya que contiene más reservas que propician plántulas más grandes y capacidad mayor para crecer.

Los resultados permiten sugerir que en $O$. rosea existe un posible vínculo entre el control del tamaño de la semilla y el crecimiento de los órganos de la planta. Aunque, el tamaño de las semillas y de los órganos puede estar relacionado positiva o negativamente. Al respecto, Turnbull et al. (Turnbull, L. A., Philipson, C. D., Purves, D. W., Atkinson, R. L., Cunniff, J., Goodenough, A., ... Rees, 2012) indicaron que las semillas y los órganos pueden poseer vías comunes y distintas para controlar su tamaño respectivo.

\section{CONCLUSIONES}

Las semillas silvestres de $O$. rosea muestran cierta homogeneidad en tamaño de semilla dentro y entre sitios de recolecta. En condiciones estándar de germinación y en dependencia del tamaño de semilla y del sitio de recolecta puede germinar entre 20 y $90 \%$. Pero su potencial germinativo se incrementa en condiciones de invernadero. La multiplicación sexual de esta especie en condiciones protegidas permite la multiplicación y desarrollo de las plantas hasta el final de la etapa reproductiva; por lo que, en esas condiciones puede obtenerse follaje, tallos, raíces y semillas con uso potencial en herbolaria y plantas para ornato. Además, ya que, durante el desarrollo, las etapas fenológicas se traslapan su cultivo permitiría disponibilidad de plantas en las etapas diversas de desarrollo simultáneamente.

El tamaño de la semilla está asociado significativamente con la altura del tallo, el número de yemas florales, el número de cápsulas maduras y longitud de la raíz después de 110 días de cultivo. Aunque otras variables del crecimiento, como el diámetro del tallo y la anchura, la longitud o el número promedio de las hojas durante el crecimiento parecen independientes del tamaño de la semilla.

\section{LITERATURA CITADA}

Aguirre R., J. R., Peña-Valdivia, C. B., y Bayuelo-Jiménez, J. S. (2003). Morphology, phenology and agronomic traits of two wild Mexican common bean (Phaseolus vulgaris L.) populations under cultivation. South African Journal of Botany, 69(3), 410-421.

Al-Karaki, G. N. (1998). Seed size and water potential effects on water uptake, germination and growth of lentil. Journal of Agronomy and Crop Science, 181, 237-242. 
Almora-Pinedo, Y., Arroyo-Acevedo, J., Herrera-Calderon, O., Chumpitaz-Cerrate, V., HañariQuispe, R., Tinco-Jayo, A., ... Figueroa-Salvador, L. (2017). Preventive effect of Oenothera rosea on N-methyl-N-nitrosourea- (NMU) induced gastric cancer in rats. Clinical and Experimental Gastroenterology, 10, 327-332.

Andrade-Cetto, A. (2009). Ethnobotanical study of the medicinal plants from Tlanchinol, Hidalgo, México. Journal of Ethnopharmacology, 122, 163-171.

Berrocal I., S., Ortíz C., J., y Peña-Valdivia, C. B. (2002). Yield components, harvest index and leaf area efficiency of a sample of wild population and a domesticated variant of the common bean. South African Journal of Botany, 68, 205-211.

Brunner, I., Herzog, C., Dawes, M. A., Arend, M., y Sperisen, C. (2015). How tree roots respond to drought. Frontiers in Plant Science, 6, 1-16.

Calderón de Rzedowski, G., y J. R. (2001). Flora fanerogámica del Valle de México.

Calva-Candelaria, N., Meléndez-Camargo, M. E., Montellano-Rosales, H., Estrada-Pérez, A. R., Rosales-Hernández, M. C., Fragoso-Vázquez, M. J., ... Márquez-Flores, J. K. (2018). Oenothera rosea L'Hér. ex Ait attenuates acute colonic inflammation in TNBS-induced colitis model in rats: in vivo and in silico myeloperoxidase role. Biomed. Pharmacotherapy, 108, 852-864.

Chouard, P. (1960). Vernalization and its relation to dormancy. Annual Review of Plant Physiology, 11, 191-238.

Clough, E. A., Cameron, A. C., Heins, R. D., y Carlson, W. H. (2001). Growth and development of Oenothera fruticosa is influenced by vernalization duration, photoperiod, forcing temperature, and plant growth regulators. Journal of the American Society for Horticultural Science, 126(3), 269-274.

Clough, E. A., Cameron, A.C., Heins, R. D., y Carlson, W. H. (1999). Forcing perennials crop by crop. Species: Oenothera fruticosa 'Youngii-lapsley.' Greenhouse Grower, 17(10), 50-60.

Dahiya, S. S., Kaur, R., y Sharma, S. K. (2012). Evaluation of in vitro anthelmintic activity of Oenothera rosea L'Hér. ex Aiton. stem and root. Journal of Natural Product and Plant Resources, 2(4), 534-539.

Deng, Y-C., Hua, H. M., Li, J., y Lapinskas, P. (2001). Studies on the cultivation and uses of evening. primrose (Oenothera spp.) in China. Economic Botany, 55(1), 83-92.

Díaz P., H. V., Fuertes R., C., Whu W., D., Jurado T., D., Roque A., M., y Arroyo A., J. (2011). Efecto antiagregante plaquetario in vivo y fibrinolítico in vitro del extracto etanólico de las hojas de Oenothera rosea Aiton (chupasangre). Revista de La Sociedad Química Del Perú, 77(3), 225-234.

Elizalde, V., García, J. R., Peña-Valdivia, C. B., Ybarra, M. C., Leyva, O. R., y Trejo, C. (2017). Viabilidad y germinación de semillas de Hechtia perotensis (Bromeliaceae). Revista de Biología Tropical, 65(1), 153-165.

Ensminger, P. A., y Ikuma, H. (1987). Photoinduced seed germination of Oenothera biennis L. II. Analysis of the photoinduction period. Plant Physiology, 85, 885-891.

Ensminger, P. A., \& Ikuma, H. (1987). Photoinduced Seed Germination of Oenothera biennis L. Plant Physiology, 85, 879-884. https://doi.org/10.1104/pp.86.2.475

Erskine, W. (1996). Seed-size effects on lentil (Lens culinaris) yield potential and adaption to temperature and rainfall in West Asia. The Journal of Agricultural Science, 126, 335341.

Fan, C., Yu, S., Wang, C., y Xing, Y. (2009). A causal C-A mutation in the second exon of GS3 highly associated with rice grain length and validated as a functional marker. Theoretical and Applied Genetics, 118, 465-472.

Ferreyra, R. (1986). Flora del Perú. Dicotiledóneas.

Gan, Y., y Stobbe, E. H. (1995). Effect of variations in seed size and planting depth on emergence, infertile plants, and grain yield of spring wheat. Canadian Journal of Plant Science, 75, 565-570.

García, E. (1988). Modificaciones al sistema de clasificación climática de Köppen.

Giménez, R., Sorlino, D. M., Bertero, H. D., y Ploschuk, E. L. (2013). Flowering regulation in the facultative biennial Oenothera biennis L.: environmental effects and their relation 
to growth rate. Industrial Crops and Products, 44, 593- 599.

Gómez-Flores, R., Reyna-Martínez R., Tamez-Guerra, P., y Quintanilla-Licea, R. (2012). Antibacterial activity of Oenothera rosea (L 'Hér) leaf extracts. British Journal of Medicine and Medical Research, 2, 396-404.

Gómez J. M., y Husband, B. (2004). Bigger is not always better: conflicting selective pressures on seed size in Quercus ilex. Evolution, 58, 71-80.

Greiner, S., y Köhl, K. (2014). Growing evening primroses (Oenothera). Frontiers in Plant Science, 5, 1-12.

ISTA. (2005). International rules for seed testing. Seed Science \& Technology, 27.

Jha, B. B., Sinha, S. K., y Singh, C. N. (1985). Effect of seed size on yield in wheat. Seed Research, 13, 24-27.

Kaur, R., Ali, M., Dahiya, S. S., Sharma, S. K., Sultana, S., y Mir, S. R. (2017). Phytochemical investigation of Oenothera rosea L'Hér. Ex Aiton. International Journal of Pharma and Bio Sciences, 4(4), 24-31.

Kitajima, K., y Myers, J. A. (2008). Seedling ecophysiology: strategies towards achievement of positive net carbon balance. In Seedling Ecology and Evolution (pp. 172-188).

Li N., y Li, Y. (2015). Maternal control of seed size in plants. Journal of Experimental Botany, 66, 1087-1097.

Márquez-Flores, Y. K., Montellano-Rosales, H., Campos A., M. E., y Meléndez-Camargo, M. E. (2009). Anti-inflammatory activity of aqueous and methanolic extracts of Oenothera rosea L' Hér. ex Ait in the rat. Revista Mexicana de Ciencias Farmacéuticas, 40(3), 11-16.

Martínez, A. L. (2015). Herbolaria mexicana para el tratamiento del dolor. Ciencia, julio-sept, 60-68.

Meckes, M., David-Rivera, A.D., Nava-Aguilar, V., y Jimenez, A. (2004). Activity of some Mexican medicinal plant extracts on carrageenan-induced rat paw edema. Phytomedicine, 11, 446-451.

Metz, J., Liancourt, P., Kigel, J., Harel, D., Sternberg, M., y Tielbo, K. (2010). Plant survival in relation to seed size along environmental gradients: a long-term study from semi-arid and Mediterranean annual plant communities. Journal of Ecology, 98, 697-704.

Mian, M. A. R., y Nafziger, E. D. (1994). Seed size and water potential effects on germination and seedling growth of winter wheat. Crop Science, 34, 169-171.

Moles, A. T., Ackerly, D. D., Webb, C. O., Tweddle, J. C., Dickie, J. B., y Westoby, M. (2005). A brief history of seed size. Science, 307, 576-580.

Ormeño, N. J. (2006). Calahuala, epilobium y enotera rosada. Malezas de frutales que no son controladas con glifosato. Tierra Adentro, noviembre-, 26-29.

Peña-Valdivia, C. B., Aguirre-Rivera, J. R., y Arroyo-Peña, V. B. (2012). El Frijol Silvestre: Síndrome de Domesticación.

Pérez, M. C., Hernández, L. A., González, C. F. V., García de los Santos, G., Carballo, C. A., Vásquez, R. T. R., y Tovar, G. M. R. (2006). Tamaño de semilla y relación con su calidad fisiológica en variedades de maíz para forraje. Agricultura Técnica en México, $32,341-352$.

Picard, C. (1965). Contribution a la connaissance de la vernalisation, de ses particularités et de sa signfication chez Oenothera biennis L. var. sulfurea De Vries. Annales Des Sciences Naturelles, Botanique, 6, 197-314.

Poorter, L., Wright, S. J., Paz, H., Ackerly, D. D., Condit, R., Ibarra-Manríquez, G., ... Licona J. C. (2008). Are functional traits good predictors of demographic rates? Evidence from five Neotropical forests. Ecology, 89, 1908-1920.

Rees, M., y Venable, D. L. (2007). Why do big plants make big seeds? Journal of Ecology, 95, 926-936.

Rubio de Casas, R., Willis, C. G., Pearse, W. D., Baskin, C. C., Baskin, J. M., y CavenderBares, J. (2017). Global biogeography of seed dormancy is determined by seasonality and seed size: a case study in the legumes. New Phytologist, 2014, 1527-1536.

Sihuay-Torres, K., Pérez-Jimenez, V., Turriate-Vivar, C., Portillo-Yancachajlla, E., y CastroRodríguez, Y. (2016). Efecto antiinflamatorio del extracto acuoso de Oenothera rosea 
Recibido:

17/mayo/2019

Aceptado:

3/marzo/2020 en ratas con edema subplantar inducido por carragenina. JPAPO, 1(1), 1-6.

Soria, R. (1984). Estudio farmacobotánico de Oenothera rosea L Her. Ex Ait. No Title.

Steiner, A. A. (1984). The Universal Nutrient Solution.

Tanigushi, S, Imayoshi, Y, Hatana, T, Yazaki, K, e Yoshida, T. (2002). Hydrolysable tannin production in Oenothera rosea tetrápteras shoot tissue culture. Plant Biotechnology, 19(5), 357-363.

Turnbull, L. A., Philipson, C. D., Purves, D. W., Atkinson, R. L., Cunniff, J., Goodenough, A., ... Rees, M. (2012). Plant growth rates and seed size: a re-evaluation. Ecology, 93, 1283-1289.

Venable D. L., y Rees, M. (2009). The scaling of seed size. Journal of Ecology, 97, 27-31.

Villaseñor-Ríos, J. L., y Espinosa-García, F. J. (1998). Catálogo de Malezas de México.

Villena N., C. A., y Arroyo A., J. L. (2012). Efecto antiinflamatorio del extracto hidroalcohólico de Oenothera rosea (Yawar Socco) en ratas con inducción a la inflamación aguda y crónica. Ciencia e Investigación, 15, 15-19.

Wagner, W. L., Hoch, P. C., y Raven, P. H. (2007). Revised classification of the Onagraceae. Systematic Botany Monographs, 83, 1-240.

White, I. W., Singh, S. P., Pino, C., Rios, M. J., y Buddenhagen, I. (1992). Effect of seed size and photoperiod response on crop growth and yield of common bean. Field Crops Research, 28, 295-307.

Wiesner, M. B. (1991). Enchanted evenings: get to know Oenothera and dusk may be your favorite time of day. American Horticultural, 70, 16-21. 